\title{
O DIREITO À SEGURANÇA NA ERA VIRTUAL: AS IMPLICAÇÕES NO DIREITO CONSTITUCIONAL
}

\author{
Dissertação de Mestrado \\ Orientador: Prof. Dr. Alexandre de Moraes
}

UNIVERSIDADE DE SÃO PAULO

FACULDADE DE DIREITO

São Paulo - SP 


\title{
O DIREITO À SEGURANÇA NA ERA VIRTUAL: AS IMPLICAÇÕES NO DIREITO CONSTITUCIONAL.
}

\begin{abstract}
Dissertação apresentada à Banca examinadora do Programa de PósGraduação em Direito, da Faculdade de Direito da Universidade de São Paulo, como exigência parcial para a obtenção do título de Mestre em Direito, na área de concentração Direito do Estado, sob a orientação do Prof. Dr. Alexandre de Moraes.
\end{abstract}

\section{UNIVERSIDADE DE SÃO PAULO \\ FACULDADE DE DIREITO}

São Paulo - SP 
Nome: RAMALHO, Alex Saito

Título: O direito à segurança na era virtual: as implicações no Direito Constitucional.

Dissertação apresentada como requisito para conclusão do programa de Pós-Graduação Stricto Sensu/ nível Mestrado da Faculdade de Direito da Universidade de São Paulo.

Área de Concentração: Direito do Estado

Orientador: Prof. Dr. Alexandre de Moraes

Examinado em: de de 2017

Resultado:

\section{BANCA EXAMINADORA}

Prof. Dr: Instituição:

Julgamento: Assinatura:

Prof. Dr: Instituição:

Julgamento: Assinatura:

Prof. Dr: Instituição:

Julgamento: Assinatura: 


\section{DEDICATÓRIA E AGRADECIMENTO}

A realização deste trabalho não teria sido possível sem o apoio de algumas pessoas, que, direta ou indiretamente, contribuíram para o resultado final do mesmo. Dirijo uma palavra de apreço e gratidão à minha família pelo apoio e amor incondicional.

Desse modo, agradeço e dedico esse trabalho especialmente à minha mãe, Alhis Saito Ramalho, e ao meu pai, Marco Antonio Fares Ramalho - pessoas, cidadãos e médicos exemplares - que nunca deixaram a base estremecer, apoiando-me sempre na realização dos meus sonhos e amparando as minhas quedas.

Dedico também aos meus avôs, Obedio Saito (in memorian) e José da Costa Ramalho, por serem modelos de ética, caráter e profissionalismo. Características tão ausentes na sociedade brasileira. Assim como, dedico as minhas avós, Arlette de Oliveira Fidalgo Saito, e Rosa Fares Ramalho, por todo carinho e afeto que sempre recebi.

À Carolina, meu muito obrigado por compreender as horas furtadas de sua companhia, e pelo total apoio que me tem sido dispensado.

Agradeço por fim, ao professor Alexandre de Moraes, pela confiança e pela oportunidade de continuar meus estudos acadêmicos na Faculdade de Direito da Universidade de São Paulo. 


\section{RESUMO}

Nos últimos anos, a celeridade da evolução tecnológica tem provocado inúmeras alterações na sociedade e nos modos de relacionamento entre as pessoas. A internet, o ciberespaço, a sociedade de informação e outros conceitos surgiram provocando a necessidade de atualização dos paradigmas jurídicos clássicos. Assim, o Estado e seus elementos, como a soberania e o território, sofrem fortes impactos em suas características, e consequentemente, precisam ser atualizados para responderem de maneira adequada aos desafios hodiernos. $\mathrm{O}$ mundo transformou-se numa complexa teia de redes interligadas, onde a internet, além de trazer aspectos positivos, também é promotora de novos perigos e desafios, entre eles a vulnerabilidade dos direitos humanos. A insegurança no ciberespaço, demonstrada pela facilidade e abrangência do monitoramento de dados e controle de informações de cidadãos de qualquer Estado em qualquer lugar do mundo, torna premente o estudo da proteção do direito à segurança na era virtual. Todos os indivíduos podem ser objetos de controle de governos dos Estados e de grandes empresas de tecnologias, que inclusive podem atuar em conjunto. Assim, abordamos as limitações para a proteção dos direitos humanos fundamentais por parte dos Estados Nacionais, que já não possuem o poder de outrora, e a necessidade do desenvolvimento de um modelo de Estado que esteja aberto aos instrumentos de cooperação para o enfrentamento de problemas comuns que ultrapassam as fronteiras estatais: O Estado Constitucional Cooperativo. Neste estudo, procuramos perceber o diálogo entre as Cortes Constitucionais como um instrumento de cooperação para auxiliar a proteção aos Direitos Humanos, especialmente o Direito à Segurança. Desse modo, abordamos, na perspectiva do Direito Constitucional, conceitualmente o fenômeno da interação entre as jurisdições constitucionais, analisando em concreto a sua utilização nos dias atuais e as necessidades de aprimoramento desse instrumento de cooperação. Para alcançar as respostas pretendidas recorremos ao método de abordagem hipotético dedutivo e como método de procedimento, o estruturalista.

Palavras-chave: Internet, Ciberespaço, Soberania, Estado Constitucional, Direito à Segurança, Cooperação. 


\begin{abstract}
In recent years, the technological evolution's celerity has caused many changes in society and in ways of relationships between people. The internet, the cyberspace, the information society and others concepts emerged causing a need to update the traditional legal paradigms. Thus, the State and its elements, such as sovereignty and territory, suffer severe impacts on their characteristics, and therefore need to be updated to respond adequately to current challenges. The world has become a complex web of interconnected networks, where the internet, despite bringing positive aspects, is also a promoter of new threats and challenges, including the vulnerability of human rights. The cyberspace insecurity is demonstrated by the ease and comprehensiveness of the data monitoring and control information of citizens of any State anywhere in the world, makes pressing the study of the protection of constitutional right to security in the virtual era. All individuals can be objects of control of governments or technologies companies, which also can act together. Therefore, it was addressed the limitations for the protection of fundamental human rights by the National States which no longer have the power that they had once, and the need to develop a state model that is open to cooperation instruments for dealing with common problems that cross state borders: the Cooperative Constitutional State. In this study, we seek to realize the dialogue between the Constitutional Courts as a cooperation tool to help protect human rights, especially the right to security. Consequently, we approach from the perspective of constitutional law, the concept of the phenomenon of interaction between constitutional jurisdictions, analyzing their use in practice nowadays and the improvement necessary of this cooperation instrument. To achieve the desired responses, we resorted to the hypothetical-deductive method of approach, and as a method of procedure, the structuralist.
\end{abstract}

Keywords: Internet, Cyberspace, Sovereignty, Constitutional State, Right to Security, Cooperation. 


\section{RÉSUMÉ}

Ces dernières années, la célérité de l'évolution technologique a provoqué de nombreux changements dans la société et dans les modes de relation entre les gens. L'Internet, le cyberespace, la société de l'information et d'autres concepts ont émergé entraînant un besoin de mettre à jour les paradigmes juridiques traditionnels. Ainsi, l'Etat et ses éléments, tels que la souveraineté et le territoire, souffrent de graves répercussions sur leurs caractéristiques, et donc, doivent se réinventer pour répondre adéquatement aux défis d'aujourd'hui. Le monde est devenu un complexe des réseaux interconnectés, où l'Internet, en dépit apportant des aspects positifs, il est également un promoteur de nouveaux défis et menaces, y compris la vulnérabilité des droits de l'homme. L'insécurité dans le cyberespace a démontré la facilité et la couverture de la surveillance des informations et le contrôle des citoyens de tout État pour toute le monde, fait devenir urgente l'étude de protection de le droit à la sécurité dans l'ère virtuelle. Tous les individus peuvent être des objets de contrôle des gouvernements des États et des grandes entreprises de technologie, qui peuvent également agir ensemble. Ainsi, nous abordons les limites à la protection des droits fondamentaux de l'homme par les Étatsnations, qui ne possèdent pas de le pouvoir de une fois déjà, et la nécessité de développer un modèle d'état qui est ouvert aux instruments de coopération pour faire face à des problèmes communs comme au-delà de frontières de l'Etat: l'Etat constitutionnel coopérative. Dans cette étude, nous cherchons à comprendre le dialogue entre les Cours constitutionnelles comme un outil de coopération pour aider à protéger les droits humains, en particulier le droit à la sécurité. Ainsi, nous nous approchons du point de vue du droit constitutionnel, conceptuellement le phénomène d'interaction entre les juridictions constitutionnelles, en analysant la pratique de leur utilisation actuellement et les besoins d'amélioration de cet instrument de coopération. Pour obtenir les réponses souhaitées, nous utilizons la méthode d'approche hypothétique-déductive et comment méthode de procédure, le struturaliste.

Mots-clés: Internet, le cyberespace, la souveraineté, l'Etat de droit. Droit à la sécurité. Coopération. 


\section{SUMÁRIO}

INTRODUÇÃO

1 CAPÍTULO I. A ERA VIRTUAL E AS MUDANÇAS NO MUNDO JURÍDICO

Pan.

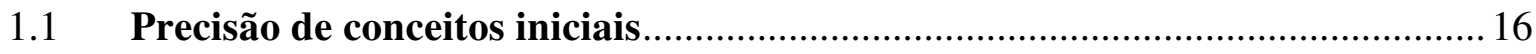

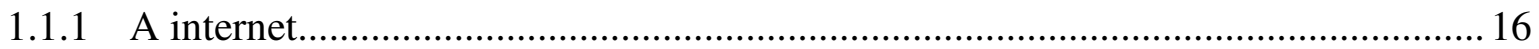

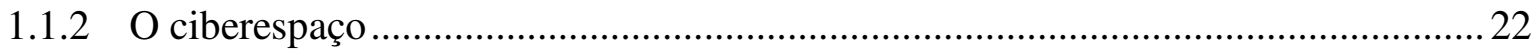

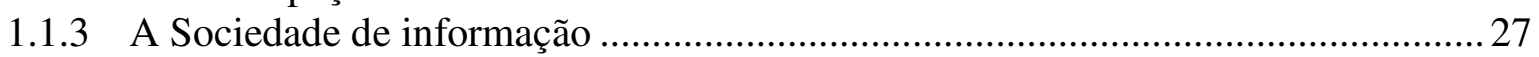

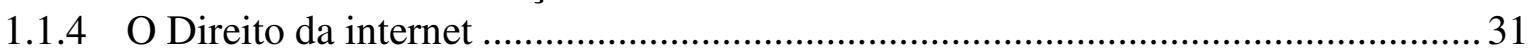

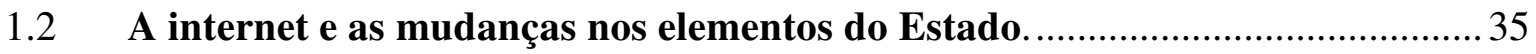

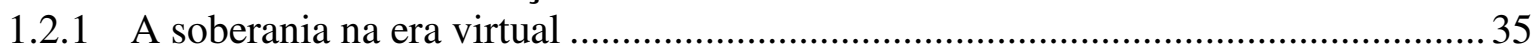

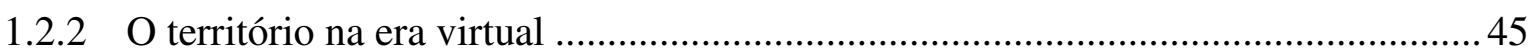

1.3 A internet e a aproximação do Direito Constitucional com o Direito

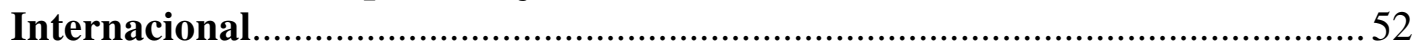

1.3.1 A violação dos Direitos Humanos no âmbito virtual ................................................54

1.3.2 A proteção dos Direitos Humanos no âmbito virtual................................................58

2 CAPÍTULO II: A ERA VIRTUAL E OS DESAFIOS A PROTEÇÃO AO

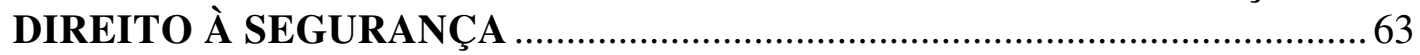

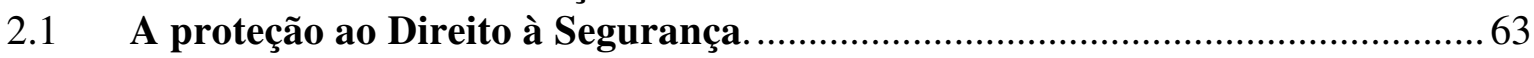

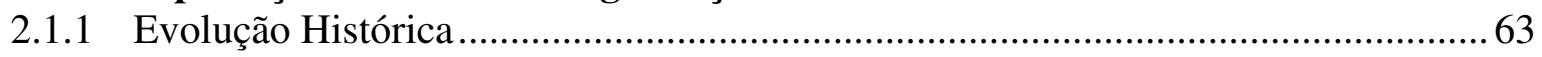

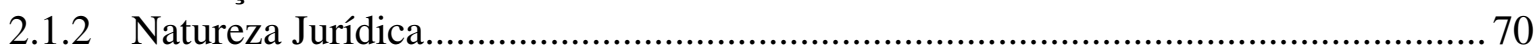

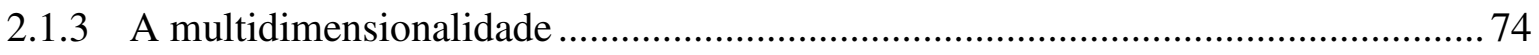

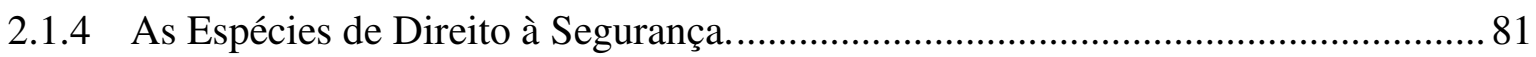

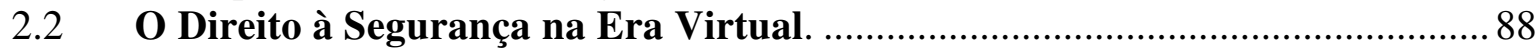

2.2.1 A internet como instrumento de violação ao direito à Segurança............................ 88

2.2.2 O ciberespaço como ambiente de violação ao Direito à Segurança. ......................... 93

2.3 Os desafios à Proteção ao Direito à Segurança. ...................................................99

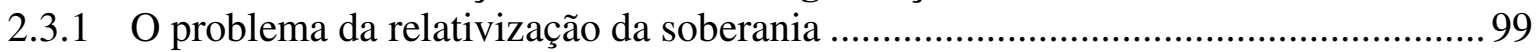

2.3.2 O problema da (des)territorialização.................................................................. 103

2.3.3 O caso Edward Swonden como deflagrador da insegurança. ................................ 105

3 CAPÍTULO III. A COOPERAÇÃO CONSTITUCIONAL COMO FORMA DE EFETIVAÇÃO DO DIREITO À SEGURANÇA. ....................................... 113

3.1 A necessidade de superação de paradigmas ................................................ 114

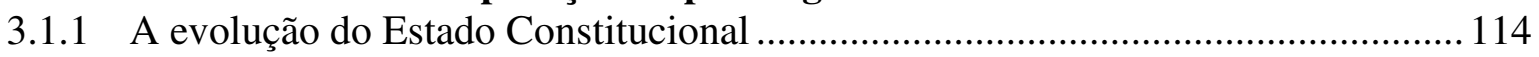

3.1.2 A limitação do Estado Constitucional Nacional .................................................. 121

3.2 A cooperação constitucional como o futuro do Estado? ..................................... 132

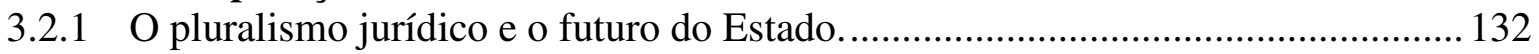

3.2.2 A viabilidade de um Estado Constitucional Cooperativo .................................... 141

3.3 A Cooperação como instrumento para a efetivação do Direito à Segurança 149

3.3.1 O Diálogo Judicial entre as Cortes Constitucionais............................................. 151

3.3.2 O fortalecimento do Sistema Internamericano de proteção aos Direitos Humanos e a adoção da estratégia interamericana integral para combater as ameaças à Segurança

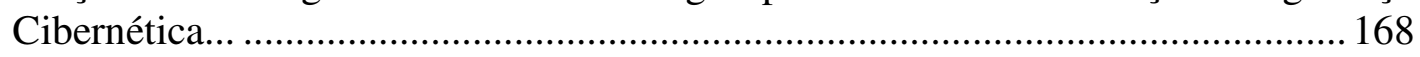

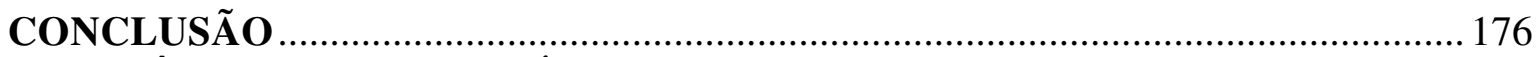

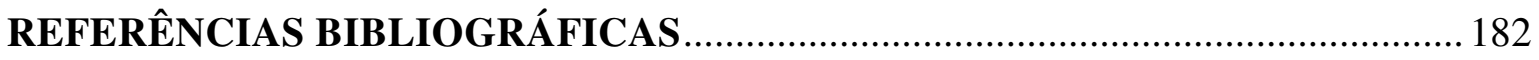




\section{INTRODUÇÃO}

Ao longo da história da humanidade, foram desenvolvidos inúmeros avanços tecnológicos, desde a utilização de instrumentos cortantes, do fogo, da roda, até a construção de máquinas movidas a combustão na Revolução Industrial. Com a comunicação e a transmissão de informação, essa evolução não foi diferente, com a criação da impressa, do rádio, da televisão até a grande revolução da computação e da internet que vivenciamos. Assim, o conhecimento e as relações sociais estão em constante transformação, de acordo o desenvolvimento tecnológico da sociedade.

Atualmente, com a evolução da internet, instrumento que melhor representa o avanço da tecnologia da informação, a intensidade e velocidade na comunicação e intercâmbio de conhecimento e informações atingiu um nível nunca antes imaginado. A evolução desta, consequentemente, provoca mudanças profundas na estrutura da sociedade e do Estado. Sem dúvida é uma das maiores revoluções ocorridas na história, trazendo um novo paradigma com consequências imprevisíveis. Assim, estamos diante de uma forma inovadora de encarar o mundo, o que faz com que os juristas contemporâneos precisem agir com sagacidade para proteção de direitos humanos que podem ser violados através das novas tecnologias que se desenvolvem em um mundo globalizado. ${ }^{1}$

Indubitavelmente, o transcurso para uma Era da Informação vem demandando a constituição de novos instrumentos de regulação política e jurídica que respondam às múltiplas questões que vem sendo suscitadas.

A globalização resulta em diversas novidades para o mundo jurídico. Entre elas, pode-se destacar a relativização das balizas geográficas estatais, sendo o desenvolvimento da informática seu grande fator de impulsão. Com esta, a transferência de informações e de sua segurança ganharam contornos bastante significativos e fomentam a necessidade de atuação da esfera jurídica. ${ }^{2}$

Os meios de comunicação de massa romperam as fronteiras nacionais provocando uma reorganização da sociedade em rede, que está constantemente interconectada. A internet passa a desempenhar, consequentemente, um papel fundamental pois interliga o mundo à grande rede virtual, de modo que pondera Nogueira ser: “a globalização a nova

1 CATALA, Pierre. Le droit à l'épreuve du numérique: jus ex machina. Paris: Press universitaires de France, 1998, p. 225

${ }^{2}$ RIQUERT, Marcelo Alfredo. Informática y derecho penal argentino. Buenos Aires: Ad-hoc, 1999, p. 62 
mutação estatal. Seu transporte é a via internet, a rede global de comunicação, que liga todos a tudo instantaneamente. A máquina de Hobbes, o leviatã, agora tem dimensão cibernética”. ${ }^{3}$ Aqui coloca-se ao leitor a mesma questão que uma vez foi indagada ao autor, no auge do escândalo sobre a falta de segurança na internet, em 2013, e que motivou o desenvolvimento do objeto dessa dissertação: Você se sente seguro em um mundo virtual?

Essa pergunta se insere em um contexto, onde, paralelamente a utilização massiva da internet no cotidiano das pessoas, que conversam, compram, jogam, estudam, trabalham, viajam em um espaço virtual, é aberta a diversas atividades ilícitas que se proliferam pela falta de uma adequada regulamentação e proteção pelos Estados. A internet possui então, uma dupla dimensão: ao mesmo tempo que potencializa facilidades, beneficiando a sociedade com inovações em diversos aspectos, também possui fragilidades, notadamente ao nível de segurança. Essa vulnerabilidade muitas vezes passa desapercebida pelos indivíduos quando conectados à rede mundial de computadores.

As alterações implementadas na sociedade por força de um sistema de informações computadorizadas compõem uma ameaça permanente à pessoa humana e aos direitos fundamentais, como por exemplo à segurança e à privacidade, cujas violações frequentes ganharam destaque no cenário político e largo interesse no campo jurídico e internacional. Constata-se que a tecnologia pode entrar em rota de colisão com a proteção e efetivação dos direitos humanos.

Esse cenário suscita a problematização em relação às ameaças ao direito humano fundamental à segurança, que têm sobrepujado a baliza entre o direito interno de cada país, consolidando-se como uma exigência internacional. As ordens constitucionais se deparam com este fenômeno que não pode ser enfrentado pelos critérios do constitucionalismo nacional tradicional, pois convivem com o fator da internacionalização dos direitos humanos e a sua possibilidade de violação através da rede mundial de computadores, necessitando de um entrelaçamento de ordens jurídicas em diversos níveis para se viabilizar uma proteção adequada. O caso da espionagem americana é extremamente emblemático ao demonstrar ser impossível uma solução satisfatória a partir da atuação unilateral de qualquer Estado-nação.

Assim, o Direito Constitucional interno não oferece reais condições para tutelar e dirimir as controvérsias provenientes da rede de computadores, havendo a necessidade de se

\footnotetext{
${ }^{3}$ NOGUEIRA, Alberto. Globalização, regionalizações e tributação: a nova matriz mundial. Rio de Janeiro: Renovar, 2000, p. 58; Apud GUERRA, Sidney. A quarta onda globalizante e os desafios para o Direito Internacional. Revista da Faculdade de Direito de Campos, 2004. ISSN V. Disponivel em: $<$ http://www.uniflu.edu.br/arquivos/Revistas/Revista04e05/Docente/17.pdf > . Acesso em: 09 fevereiro 2015
} 
socorrer de ideias inovadoras que pretendam analisar o contexto atual, para a partir deste, buscar soluções a problemas contemporâneos.

Neste trabalho, pretende-se dar especial ênfase a dois aspectos distintos. Por um lado, procuraremos realizar uma análise de como a doutrina, tanto nacional quanto estrangeira, vem entendendo a proteção aos direitos humanos em cenário onde a globalização e a internet fomentam problemas constitucionais transfronteiriços. Por outro lado, pretendemos analisar mecanismos constitucionais para o enfrentamento dessa problemática.

O objetivo desse estudo irá restringir-se, especificamente, à investigação das implicações que o direito fundamental à Segurança sofre na era virtual e as possibilidades de fortalecimento de sua proteção jurídica, necessária devido as violações perpetradas através da internet. O estudo envolverá para tanto, a análise da teoria do Estado Constitucional Cooperativo, desenvolvida por Peter Häberle, pois esta traz inovações doutrinárias e constatações práticas relevantes no cenário em que os problemas constitucionais perpassam as fronteiras dos Estados Nacionais.

Em síntese, o que se procura nessa dissertação é a compreensão dos mecanismos de cooperação para a proteção ao Direito à Segurança, o que se fará a partir de doutrina e da prática jurídica acerca do tema, buscando alternativas para uma melhor efetivação e concretização do direito à segurança em um mundo globalizado.

A dissertação será estruturada em três capítulos. O primeiro terá como mote o exame das transformações do direito dentro de um mundo globalizado e informatizado. Inicialmente, será necessário adotar como ponto de partida, o esclarecimento de conceitos relevantes, como o da internet, do ciberespaço, da sociedade de informação e se já há uma nova área de estudo, dentro da ciência do Direito, que analise as questões advindas da internet.

Em seguida, pretende-se abordar as principais consequências apontadas pela doutrina quanto ao impacto da internet sobre os elementos do Estado no mundo contemporâneo. Nessa sociedade pós-moderna, há a constatação de que "o território se tornou menos estaque, a população menos exclusiva, a soberania menos indivisível". ${ }^{4}$ Após expostos os modelos, especialmente sobre a afetação que a internet provoca no Estado territorial soberano, passaremos à análise de como tem sido, historicamente, a relação entre o Direito Constitucional e o Direito Internacional, para verificarmos a aproximação entre

\footnotetext{
${ }^{4}$ PIRES, Francisco Lucas. Introdução ao Direito Constitucional Europeu. Coimbra, livraria Almedina,
} 1997, p.8. 
ambos proporcionada pela internet. Consequentemente, como ocorrem as violações e a proteção aos direitos humanos no ambiente virtual a partir do estreitamento entre o Direito Constitucional e o Direito Internacional.

Já no segundo capítulo, ainda sob o enfoque doutrinário, o exame concentrar-se-á, principalmente, na análise do direito à segurança, verificando sua evolução histórica, características, natureza jurídica, peculiaridades e espécies. Destarte, examinaremos os dispositivos constitucionais que consagram e prescrevem o direito à segurança. Após, será o momento do estudo do direito à segurança na era virtual, quando será verificado o papel da internet e do ciberespaço em relação a este direito humano fundamental. A primeira, pode ser compreendida como um instrumento de violação ao direito à segurança e o segundo pode se configurar como um ambiente propicio a estas violações. A partir de então, será necessário aprofundar o estudo em relação aos desafios à proteção ao Direito à Segurança, especialmente quanto aos problemas da relativização da soberania e da desterritorialização, que dificultam a atuação do Estado. Como ilustração e evidência concreta será abordado o escândalo que ficou conhecido como caso Snowden, onde foi revelada a existência de programas do governo americano para o controle e monitoramento das informações transmitidas pela rede mundial de computadores, escancarando a insegurança existente na atual estrutura da rede virtual.

Por fim, no terceiro capítulo, será realizada uma tentativa de compreender a chamada crise do Estado Nacional. Para tanto, partiremos da evolução do Estado Constitucional nos últimos séculos, para posteriormente verificarmos a limitação atual do Estado Constitucional Nacional. O exame das principais doutrinas sobre o tema objetiva enfocar, sobretudo, quais são os possíveis limites impostos à atuação do Estado Nacional, especialmente quanto ao poder de aplicar o direito em seu território, e se há necessidade de se buscar novos paradigmas para ocuparem o lugar deste no do arcabouço teórico políticojurídico da contemporaneidade.

Então, entraremos no exame de desenvolvimento de um Estado Constitucional Cooperativo, teorizado pelo constitucionalista alemão Peter Häberle, que propõe a adição de elementos de cooperação e integração à estrutura fechada do Estado centrada na soberania nacional. Assim, as bases serão as doutrinas que se debruçaram a estudar qual é a perspectiva do futuro do Estado diante das características da sociedade pós-moderna, como o pluralismo constitucional. Então, verificaremos a viabilidade do Estado Constitucional Cooperativo para solucionarmos a questão: o futuro do Estado passa pela incorporação de instrumentos de cooperação constitucional? 
No último tópico, portanto, será discutida a posição atual do Direito Constitucional para a concretude do direito à segurança dentro de um espaço cibernético que ultrapassa as fronteiras estatais a partir de dois instrumentos de cooperação, quais sejam: o diálogo judicial entre as Cortes Constitucionais e o fortalecimento do Sistema Interamericano de proteção aos Direitos Humanos e a adoção de uma estratégia interamericana para combater as ameaças à segurança cibernética. Para tanto, serão utilizadas as principais doutrinas que identificaram a vulnerabilidade do direito fundamental à segurança no contexto da globalização e da sociedade de informação, assim como a conferência de jurisprudência do Supremo Tribunal Federal, considerando o diálogo com jurisprudências entre diversos países e também com a Corte Interamericana de Direitos Humanos. Com estas, pretende-se verificar qual é o conceito que o Supremo Tribunal Federal confere ao constitucionalismo cooperativo e como este vem sendo aplicado; se há algum diálogo em casos sobre direitos humanos que afetem diversos Estados simultaneamente.

Em suma, a intenção do presente estudo é analisar a relevância e necessidade do aprofundamento da abertura constitucional que permita um maior diálogo de cooperação entre os sistemas jurídicos estatais para que seja possível fomentar uma maior proteção ao direito fundamental à segurança em uma era virtual e combater, por exemplo, a espionagem norte-americana. Depois de constatada como a doutrina e a jurisprudência vêm enfrentando tais assuntos, pretendemos realizar uma análise crítica de tais entendimentos.

Para tal finalidade, recorremos ao método de abordagem hipotético dedutivo e, como método de procedimento, o estruturalista. Pretendemos um estudo de carácter do teórico, em complemento com uma análise descritiva, baseando-nos na análise documental, bibliográfica, quer de fontes nacionais, quer de fontes internacionais. Deste modo, procedeuse ao levantamento bibliográfico, através da revisão de literatura, nos conceitos chave para este trabalho, de forma a embasarmos a orientação seguida. Pretende-se com isso contribuir para uma melhor interpretação da proteção aos direitos humanos na pós-modernidade. Também, não se desprezou o método analítico-sintético, com análise de posições doutrinárias em face do problema em questão e do método comparativo, examinado a legislação, a doutrina e a jurisprudência estrangeira e a atuação da Jurisdição Constitucional em alguns países, com sua possível influência nas proposições de soluções no tocante ao ordenamento pátrio.

Por derradeiro, reconhece-se que a dissertação é ousada no tema, porém se demonstra modesta na pretensão. Não objetiva esgotar o assunto, ainda pouco desenvolvido na doutrina, nem tampouco elaborar uma nova teoria de Estado. Não obstante, procurou-se estruturar a 
pesquisa em sólidos e atualizados aportes doutrinários nacionais e estrangeiros, como forma de alicercear os argumentos postos. A pretensão é estimular a discussão e o estudo acadêmico para o fortalecimento da proteção aos direitos humanos, principalmente através da cooperação, em uma época onde os novos meios tecnológicos de comunicação afetam diretamente os elementos clássicos do Estado Constitucional. 


\section{CONCLUSÃO}

A expansão dos novos meios de comunicação provocou a reorganização da sociedade em rede que se mantem sempre interconectada. Com o rompimento das fronteiras estatais, a internet passa a desempenhar a função de ligação entre o mundo real e o mundo virtual. Essa sociedade em rede inseriu o ciberespaço como um lugar de alcance mundial onde é possível realizar praticamente todas as atividades cotidianas, com uma extraordinária rapidez e eficiência entre as interações sociais e comerciais.

Todavia, para além dos benefícios, com a intensa migração do mundo real para o mundo virtual, houve o surgimento da problemática da garantia e proteção dos direitos humanos nesse ambiente, uma vez que o poder estatal já não possui a mesma capacidade de atuação. Desse modo, é exigido que haja uma resposta adequada frente à esta questão, mediante a elaboração de estratégias que devem ser consideradas como os novos desafios do futuro próximo.

Com fulcro no desenvolvimento dos capítulos que integram esta pesquisa, a linha do trabalho se orientou pela demonstração do atual cenário decorrente da revolução tecnológica, onde a internet é um dos fatores de modificação dos elementos modernos de soberania e território, e consequentemente, do Estado Nacional. Assim, não haveria mais correspondência entre a estrutura deste e a realidade globalizada hodierna.

O desenvolvimento da análise do problema proposto para esta dissertação ocorreu a partir a percepção das diversas lacunas nessa temática, que geram a incapacidade do Estado Constitucional em promover a concretização dos direitos humanos na era virtual. O interesse dessa pesquisa foi, desse modo, contribuir com o reconhecimento desse problema contemporâneo e estimular novos estudos para a construção de um ambiente onde os direitos humanos não estejam tão vulneráveis, visto ser preciso ter uma visão para além dos limites do Estado.

No âmbito do Direito Constitucional, especificamente, visualizou-se aqui a possibilidade do desenvolvimento do Estado Constitucional Cooperativo com o aprofundamento de formas de cooperação entre as Cortes Constitucionais, como um instrumento que auxilie a efetivação dos direitos humanos em uma sociedade de informação marcada pela transnacionalidade. 
Assim, do que foi referido ao longo do trabalho, a partir dessa delimitação proposta, importa em modo de conclusão sintetizar as questões abordadas e os resultados das ideias expostas que formaram a linha de pensamento desenvolvida.

No primeiro capítulo foi demonstrado como o advento da internet provocou mudanças sem precedentes na história da humanidade, cujas consequências impactaram as relações sociais e jurídicas em âmbito mundial. Entre elas está a afetação no Estado territorial soberano, agora desafiado pela limitação do exercício da soberania, que perdeu uma parcela de autonomia e de independência, e a queda das barreiras geográficas das fronteiras. A internet transpassa as fronteiras conectando diretamente os indivíduos, o que dificulta o controle do poder soberano estatal. Conforme Silveira e Campello, é necessário reformular o conceito de soberania, uma vez que os Estados não são autossuficientes, isto é, são interdependentes nas relações internacionais, não conseguindo atuar individualmente. ${ }^{1}$ Vimos também, que apesar das limitações da soberania estatal, ela apenas passa por uma época de transformações de suas características sendo precipitado considerar, por esse motivo, a falência do Estado. Esse deve se adequar à sociedade contemporânea.

O conceito de Estado necessita, então, se reinventar a partir das novas experiências da sociedade, já que as tradicionais maneiras de proteção e garantia dos direitos humanos, centralizadas no Estado, não respondem de maneira eficaz aos novos desafios da sociedade globalizada. Os diretos humanos hoje transcendem a esfera local, devendo sua proteção ser realizada em uma perspectiva global, visto que os Estados isoladamente não possuem capacidade para realizar sua tarefa de proteção e garantia aos direitos dos seus cidadãos. Não há mais espaço para a individualidade e o isolamento dos Estados, sem limites na ordem externa. Portanto, vimos que é essencial que o Estado encontre soluções contra as novas formas de violação aos direitos humanos, perpetradas através da internet.

Assim, o segundo capítulo desse trabalho foi dedicado ao estudo de um direito humano em especial, a segurança, já que esta possui a peculiaridade de ser multidimensional, representando características de direitos humanos pertencentes a todas as dimensões. Adentramos nas formas de violações a este direito na era virtual, assim como sua perspectiva de proteção normativa. Conferimos que a segurança é configurada constitucionalmente como um direito humano fundamental, que se encontra consagrado em diversas constituições ao redor do mundo. Por isso, o Estado possui o papel primordial e

\footnotetext{
${ }^{1}$ SILVEIRA, Vladmir Oliveira da; CAMPELLO, Lívia Gaigher Bósio. Cidadania e direitos humanos. In MORAES, Alexandre de; KIM, Richard Pae (Coord.). Cidadania: o novo conceito jurídico e a sua relação com os direitos fundamentais individuais e coletivos. São Paulo: Atlas, 2013. p. 116
} 
insubstituível de proteger os seus cidadãos frente às ameaças originadas no mundo globalizado. A complexidade em sua efetivação consiste, conforme visto, por tratar-se de conceito polissêmico, possuindo diversas espécies como a segurança individual, a segurança pública, a segurança nacional, e a recente cibersegurança.

Como foi demonstrado no decorrer do presente trabalho, a internet e o ciberespaço, são respectivamente o instrumento e o ambiente para novas ameaças ao direito à segurança. Os indivíduos, quando conectados à rede estão vulneráveis diante de dezenas de atividades ilícitas possíveis, que no ciberespaço adquirirem as características de transnacionailidade, do anonimato e da automação. Essas praticamente inviabilizam uma atuação efetiva do Estado na proteção dos cidadãos. Consequentemente, procuramos demonstrar que o espectro de ameaças que colocam em causa a segurança dos Estados é complexo, global e transversal às sociedades.

O tamanho da insegurança fica evidenciado quando até o próprio programador de uma das redes sociais mais usadas no mundo, Mark Zukerberg, foi flagrado utilizando uma fita adesiva para tampar a webcam e o microfone de seu computador pessoal, na tentativa de evitar seu monitoramento. Dessa forma, os acontecimentos recentes não deixam margem para que o problema seja negligenciado ou ignorado.

A existência das ameaças virtuais é uma realidade que naturalmente crescerá em periculosidade e em complexidade, gerando a necessidade dos Estados desenvolverem serviços especializados e eficazes. Todavia, é necessário refletir também sobre os instrumentos jurídicos e mecanismos jurisdicionais que auxiliem na proteção dos direitos humanos.

Portanto, é preciso, primeiro, reconhecer a falta de segurança na proteção dos usuários da internet e a insuficiência da legislação sobre o tema, tanto no âmbito nacional como no internacional, para então pensarmos soluções jurídicas para coibir as violações ao direito à segurança.

Partindo da premissa de que a segurança no espaço virtual exige um combate sistêmico em diversos planos, abordamos esta questão, no terceiro capítulo, sob a ótica do Direito Constitucional. A proposta que colocamos foi a intensificação da lógica de cooperação entre os Estados Nacionais e especialmente as ocorridas no âmbito das jurisdições constitucionais.

$\mathrm{Ou}$ seja, privilegiou-se neste trabalho a conferência de um instrumento para promover o direito à segurança no seio do Estado Constitucional, com a análise dos caminhos que devem ser percorridos, após a compreensão das características do mundo 
virtual contemporâneo, especialmente, quanto a possibilidade de cooperação constitucional, por permitir respostas jurídicas concretas.

Desse modo, para a concretização de uma sociedade de segurança, com prevalência dos direitos humanos, de respeito entre Estados e da cooperação entre os povos para o progresso da humanidade, o ponto de partida foi a evolução histórica do Estado Constitucional. Como foi constatado, em um ponto em que o autor concorda com a posição da professora Nina Ranieri, o Estado Nacional enfrenta uma crise na perspectiva de mudança de paradigma - e não uma crise na perspectiva de perecimento, de ruína - o que provoca a necessidade de uma revitalização de suas estruturas. Por isso, a análise de qual é a perspectiva do futuro do Estado se fez necessária. Não se defende a simples superação do Estado-Nação, já que o conceito de soberania foi apenas relativizado, ainda resolvendo alguns aspectos internos. Assim, a soberania não deve mais ser compreendida como o exercício do poder sobre um território, mas como o poder de cooperação com os demais Estados, em uma interação que aumenta o próprio poder destes. ${ }^{2}$

O que se revelou importante pelo recorte aqui proposto, diante de uma sociedade de informação marcada pelo pluralismo jurídico, é a exigência de uma predisposição para a cooperação constitucional, como, por exemplo, com o aprofundamento do mencionado diálogo constitucional, que as decisões de outras cortes sejam efetivamente consideradas no debate de concretização dos direitos fundamentais.

Ao se visualizar o Estado Constitucional não mais vinculado aos elementos nacionais, mas aberto à lógica da cooperação, entende-se a necessidade de desenvolvimento do que Peter Härbele idealizou e denominou de Estado Constitucional Cooperativo, que possibilita uma ampla articulação internacional a partir do afastamento dos óbices da soberania e do território segundo concepções clássicas. Isso quer dizer que o Estado Constitucional aberto à lógica da cooperação conseguirá responder melhor aos desafios trazidos pela era virtual. Desse modo, o modelo de Estado Constitucional Cooperativo se amolda mais adequadamente às concepções atuais de soberania e território já que se estrutura no questionamento sobre a impermeabilidade da soberania e da diluição das fronteiras estatais, provocando o afastando dos óbices dos conceitos clássicos.

Vimos, neste contexto, que já ocorre o aprofundamento entre as ordens jurisdicionais nos últimos anos, porém também ficou evidente a necessidade de aprimoramento e continuidade deste sob parâmetros e diretrizes de uma agenda cooperativa, onde julgamentos

\footnotetext{
${ }^{2}$ SLAUGHTER, Anne-Marie. Sovereignty and power in a networked world order. Stanford Journal of International Law, 2004. p. 327.
} 
de cortes nacionais dialoguem com decisões de outras cortes, tanto nacionais como supranacionais. Dessa forma, é possível construir mecanismos que busquem soluções para o enfrentamento de problemas comuns.

Essas constatações têm consequências imediatas para a compreensão de que o intercâmbio de ideias que envolve interpretação, argumentação e crítica à produção de outras ordens jurídicas, necessita ser realizado a partir de uma efetiva interação jurisdicional, com análises de outras fontes para o embasamento de soluções que admitam a utilização de jurisprudência estrangeira, modificando os métodos de interpretação tradicional, o que fortalece a racionalidade e legitimidade dos julgamentos.

No Brasil, apesar de termos conferido que já há a adoção da ideia do diálogo entre cortes constitucionais, com algumas referências de jurisprudência em votos de alguns Ministros do Supremo Tribunal Federal, com participações em diversas Conferências e Fóruns para a troca de experiência e até o fornecimento de bancos de dados com sua jurisprudência e também de outros países, percebemos no decorrer da pesquisa a sua pouca profundidade. A utilização de jurisprudência estrangeira de outras Cortes Constitucionais, via de regra, tiveram a finalidade de embasar argumentos já concebidos e não de influenciar nem orientar os julgadores a partir de uma experiência prévia.

Desse modo, dentre as inúmeras hipóteses de cooperação para a efetivação de direitos fundamentais existentes, e não abordadas no presente trabalho, verificamos a necessidade de aprofundamento de duas no âmbito da justiça constitucional. A primeira possibilidade é o aprimoramento do diálogo entre Cortes Constitucionais com um efetivo intercâmbio crítico e reflexivo entre jurisprudências. A segunda, sob uma perspectiva de proteção ao direito à segurança no Brasil, é o fortalecimento do Sistema Interamericano de proteção aos Direitos Humanos, com a adoção da estratégia interamericana integral para combater as ameaças à segurança na era virtual. Assim, tanto no âmbito das Organizações dos Estados Americanos, onde já se verificam diversas formas de cooperação do governo brasileiro e demais países membros, como no âmbito da Corte Interamericana de proteção aos Direitos Humanos. Nesse sentido, é essencial a realização do diálogo constitucional com os demais países da América Latina, o que hoje é praticamente inexistente, apesar de serem países com características sociais, culturas e econômicas semelhantes, que possuem problemas comuns. Também é fundamental para o fortalecimento do sistema Interamericano de proteção dos Direitos Humanos, a consciência da necessidade do diálogo entres as Cortes Constitucionais Nacionais com a Corte Interamericana de Direitos Humanos. 
Tomando o caso da espionagem americana como ilustração, não haveria fundamento lógico em um julgamento, realizado no Brasil pelo Supremo Tribunal Federal, que verse sobre a violação do direito à segurança no espaço virtual, a utilização de citação ou fundamentação nos votos de jurisprudência proveniente da Suprema Corte dos Estados Unidos. Simplesmente porque há uma discrepância de poderes políticos e econômicos entre os dois países, sendo que um é o agente idealizador de um programa de monitoramento mundial e o outro, objeto de controle do primeiro.

Neste caso, o diálogo jurisdicional deverá ser realizado com países de características semelhantes, como os países da América Latina, que poderiam acrescentar elementos construtivos para a racionalidade crítica do julgamento, fato que inclusive fortaleceria a integração regional e o Sistema Interamericano de proteção dos Direitos Humanos.

Acredita-se que, desse modo, com o desenvolvimento dos mecanismos abordados, é possível fomentar a proteção do direito fundamental à segurança na era virtual. No plano aqui discutido, pode-se concluir que o isolamento do Estado nesta área sensível, com o desprezo aos instrumentos cooperativos, prejudicará de maneira considerável a proteção de seus cidadãos.

Enfim, o caminho trilhado neste estudo, procurando analisar os problemas presentes na era virtual e na sociedade de informação, além de demonstrar os desafios que o modelo clássico de Estado enfrenta contemporaneamente, leva-nos a conclusão que os Estados não podem ignorar o atual contexto, devendo adotar uma postura cooperativa para enfrentar as vulnerabilidades inerentes à rede virtual. 


\section{REFERÊNCIAS BIBLIOGRÁFICAS ${ }^{1}$.}

ACCIOLY, H. Manual de direito Internacional Publico. 14ª . ed. São Paulo: Saraiva, 2000.

AFRICA DO SUL, CORTE CONSTITUTIONAL. President of the Republic of South Africa and Another vs Hugo. ZACC, 18 April 1997. Disponivel em: <http://www.saflii.org/za/cases/ZACC/1997/4.html>. Acesso em: 01 setembro 2016.

ALEXANDRE, S. O autor e sua obra, Neuromancer. São Paulo: Aleph, 1991.

AMARAL JÚNIOR, A. Curso de Direito Internacional Público. $1^{\text {a }}$. ed. São Paulo: Editora Atlas, 2008.

AMARAL, R. V. A questão da soberania frente a necessidade de proteção dos Direitos Humanos. Revista de Direito do Cesusc. , n. 2, junho 2007.

AMARAL, R. V. A questão da soberania frente a necessidade de proteção dos Direitos Humanos. Revista de Direito do Cesusc, n. 2, 2007.

AMÉRICA, DEPARTAMENTO DE DEFESA DOS ESTADOS UNIDOS DA. Strategy for Operating in Cyberspace. (DoD), July 2011. Disponivel em: <http://www.defense.gov/news/d20110714cyber.pdf>. Acesso em: 25 junho 2016.

ANDRADE, V. F. D. O Direito Fundamental à Segurança Pública: análise critica do sistema constitucional brasileiro. São Paulo: Tese de Doutorado, Pontifícia Universidade Católica de São Paulo., 2010.

ARAÚJO, F. R. F. Delimitação histórica do princípio da segurança jurídica nas constituições brasileiras e suas dimensões. Anais do XIX Encontro Nacional do CONEPI, Fortaleza, junho 2010.2 Disponivel em: $<$ http://www.conpedi.org.br/manaus/arquivos/anais/fortaleza/3529.pd>. Acesso em: 20 julho 2015.

ARGENTINA. CORTE SUPREMA DE JUSTICIA DE LA NACIÓN. causa $\mathbf{n}^{\circ} \mathbf{1 7 . 7 6 8 .}$ 2005, Simón, Julio Héctor y otros s/ privación ilegítima de la libertad, etc. Buenos Aires: CORTE SUPREMA DE JUSTICIA DE LA NACION, 14 de Junio de 2005. Disponivel em: $<$ http://www.saij.gob.ar/corte-suprema-justicia-nacion-federal-ciudad-autonoma-buenosaires-simon-julio-hector-otros-privacion-ilegitima-libertad-etc-poblete-causa-17768fa05000115-2005-06-14/123456789-511-0005-0ots-eupmocsollaf>. Acesso em: 01 setembro 2016.

ARIOSI, M. D. F. As relações entre o Direito Internacional e o Direito Interno. Revista Jurídica Virtual, Brasília, v. 6, n. 63, agosto 2004. Disponivel em: $<$ http://www.planalto.gov.br/ccivil_03/revista/Rev_63/Artigos/Art_Mariangela.htm>. Acesso em: 20 abril 2016.

\footnotetext{
${ }^{1}$ De acordo com a Associação Brasileira de Normas Técnicas. NBR 6023.
} 
AYUSO TORRES, M. Después del Levitán? Sobre el estado y su signo. Madrid: Spiero, 1996.

AZAMBUJA, D. Teoria Geral do Estado. 44. ed. São Paulo: Globo, 2003.

BADIE, B. Vers la responsabilité Cosmopolique ? A Propos d'Habermas, après l'Étatnation. in Les Temps Modernes, Paris, n. 610, novembro 2000.

BANISAR, D. National Comprehensive Data Protection/Privacy Laws and Bills 2016, Nov. 2016.. Disponivel em: <https://ssrn.com/abstract=1951416>. Acesso em: 01 dezembro 2016.

BARBOSA, R. Atos inconstitucionais; Atualização Ricardo Rodrigues Gama. Campinas: Russel Editores, 2003.

BARROS, S. R. D. Três Gerações de Direitos. Disponivel em: $<$ http://www.srbarros.com.br/pt/tres-geracoes-de-direitos.cont>. Acesso em: 20 junho 2014.

BASTOS JUNIOR, L. M. P.; LOIS, C. C. Pluralismo Constitucional e espaços transnacionais: o fim da constituição ou um novo começo. In: DA SILVA, A. S. O judiciário e o discurso dos Direitos Humanos. Recife: Ed. Universitária da UFPE, 2011.

BAUMAN, Z. O mal estar da pós-modernidade. Tradução de Mauro Gama e Cláudia Martinelli Gama. Rio de Janeiro: Jorge Zahar, 1998.

BECK, U. La mirada cosmopolita o la guerra es la paz. Barcelona: Paidòs, 2005.

BECK, U. A reinvenção da política: rumo a uma teoria da modernização reflexiva. In: BECK , U.; GUIDDENS , A.; LASH, S. Modernização reflexiva: política, tradição e estética na ordem social moderna. Tradução de Magda Lopes. $2^{a}$. ed. São Paulo: UNESP, 2012.

BEDIN, G. A sociedade internacional clássica: aspectos históricos e teóricos. Congresso Internacional Direitos Humanos: emancipação. ed. Ijuí: Unijuí, 2011.

BELL, D. O advento da Sociedade Pós-Industrial: uma tentativa de previsão social. Tradução de Heloysa de Lima Dantas. São Paulo: Editora Cultrix, 1973.

BELL, D. The Social Framework of the Information Society. [S.1.]: In forester, 1980.

BIELEFELDT, H. Filosofia dos direitos humanos. São Leopoldo: Ed. Unisinos, 2005.

BOBBIO, ; MATTEUCCI, ; PASQUINO, G. Dicionário de política. Tradução de Varriale Carmen C; João Ferreira e Luis Guerreiro Pinto Cacais. 11 ${ }^{\mathrm{a}}$. ed. Brasilia: Editora Universidade de Brasilia, v. 2, 1998. Vol 1: 674 p. (total 1.330) p.

BOBBIO, N. A Era dos Direitos. 7 $7^{\text {a }}$ reimpressão. ed. Rio de Janeiro: Elsevier, 2004.

BOBBITT, P. A Guerra e a Paz na História Moderna: o impacto dos grandes conflitos e da política na formulação das nações. Tradução de Cristiana Serra. Rio de Janeiro: Campus, 2003.

BODIN, J. Los seis Livros de la Republica. Livro I. Madrid: Aguilar Ediciones. 
BONAVIDES, P. Curso de Direito Constitucional. 15a . ed. São Paulo: Malheiros, 2004.

BONAVIDES, P. A quinta geração de direitos fundamentais. Revista de Direitos fundamentais e justiça, Porto Alegre, n. 3, p. 82-93, junho 2008.

BONAVIDES, P. E. A. As constituições brasileiras: notícia, história e análise crítica ; coordenação Cléa Carpi da Rocha [et al.]. Brasília: OAB Editora, 2008.

BOSON, G. D. B. M. Direito internacional público: o Estado em direito das gentes. Belo Horizonte: Del Rey, 1994.

BOYLE, J. F. Cyberspace: Surveillance, Sovereignty, and Hard-Wired Censors. University of Cincinnati Law Review, n. 66, p. 177-205, 1997.

BRASIL.CONSTITUIÇÃO (1937). Constituição dos Estados Unidos do Brasil. Rio de Janeiro: $\quad$ [s.n.], $1937 . \quad$ Disponivel em: $<$ http://www.planalto.gov.br/ccivil_03/constituicao/constituicao37.htm>. Acesso em: 22 junho 2015.

BRASIL. CONSTITUIÇÃO (1967). Constituição da República Federativa do Brasil. Brasilia: $\quad$ [s.n.], $1967 . \quad$ Disponivel em: $<$ http://www.planalto.gov.br/ccivil_03/Constituicao/Constituicao67.htm>. Acesso em: 22 junho 2015.

BRASIL. CONSTITUIÇÃO (1988). Constituição da República Federativa do Brasil: Organização de Alexandre de Moraes. São Paulo: Atlas, 2000.

BRASIL, IBGE. Pesquisa nacional por amostra de domicílios, 2015. Acesso à Internet e à Televisão e Posse de Telefone Móvel Celular para Uso Pessoal 2015, 2016. Disponivel em: $<$ http://www.ibge.gov.b>. Acesso em: 22 dezembro 2016.

BRASIL. SUPREMO TRIBUNAL FEDERAL. Habeas Corpus 82.424/RS: Relator Originário: Ministro Moreira Alves. DJO -Pesquisa de Jurisprudência, Acórdãos: STF, 17 de setembro de 2003.2 Disponivel em: $<$ http://www.stf.jus.br/portal/jurisprudencia/pesquisarJurisprudencia.asp $>$. Acesso em: 01 setembro 2016.

BRASIL. SUPREMO TRIBUNAL FEDERAL. Ação direta de inconstitucionalidade $\mathbf{n}^{\mathbf{0}}$ 3510/DF - Distrito Federal. Relator: Ministro Ayres Britto. Pesquisa de Jurisprudência, Acórdãos,: $\quad$ STF, 29 de maio 2008. Disponivel em: $<$ http://www.stf.jus.br/portal/jurisprudencia/pesquisarJurisprudenc $>$. Acesso em: 01 setembro 2016.

BRASIL, SUPREMO TRIBUNAL FEDERAL. EXT 1085/Itália, Rel. Min. Cesar Peluso. Brasilia: STF, DJE 15/04/2010.

BRASIL, SUPREMO TRIBUNALFEDERAL. Ação direta de inconstitucionalidade $\mathbf{n}^{\circ}$ 4274/DF - Distrito Federal. Relator: Ministro Ayres Britto. Pesquisa de Jurisprudência, Acórdãos: STF, 23 de novembro 2011. Disponivel em: $<$ http://www.stf.jus.br/portal/jurisprudencia/pesquisarJurisprudencia.asp $>$. Acesso em: 01 setembro 2016. 
BRENNER, S. W. Cybercrime Metrics: Old Wine, New Bottles? 9. ed. [S.1.]: Virginia Journal of Law and Technology., 2004.

BRENNER, S. W. Cybercrime: Criminal Threats from Cyberspace. [S.1.]: Praeger Publishers, 2010.

BRZEZINSKI, Z. Between two Ages: America's Role in the Technetronic Era. Nova York: : Viking Press, 1971.

BUONAMICI, S. C. Direito Fundamental Social à Segurança Pública. Revistas de Estudos Jurídicos, UNESP, v. 15, 2011.

CANADA, S. C. Local 1518 v. KMart Canada. S.C.R., 09 de setembro de 1999.. Disponivel em: <https://scc-csc.lexum.com/scc-csc/scc-csc/en/item/1722/index.do. >. Acesso em: 01 setembro 2016.

CANÇADO TRINDADE, A. A. A Interação entre o Direito Internacional e o Direito Interno na Proteção dos Direitos Humanos. In: CANÇADO TRINDADE, A. A. A Incorporação das Normas Internacionais de Proteção dos Direitos Humanos no Direito Brasileiro. São José da Costa Rica/Brasília: IIDH-CICV-ACNUR-Comissão da União Européia CoEdição, 1996.

CANÇADO TRINDADE, A. A. O Direito Internacional em um mundo em transformação. Rio de Janeiro: Renovar, 2002.

CANOTILHO, J. J. G. Direito Constitucional e teoria da constituição. $7^{\circ}$. ed. Coimbra: Almedina, 2003.

CANOTILHO, J. J. G. Brancosos e interconstitucionalidade: itinerários dos discursos sobre a historicidade constitucional. $2^{\mathrm{a}}$. ed. Coimbra: Almedina, 2008.

CARVAlHAL, A. P. Z.; FERREIRA FILHO, M. G. Constitucionalismo em tempos de globalização: a soberania nacional em risco? São Paulo: Tese de Doutorado, Universidade de São Paulo, 2014.

CARVAlHO NETTO, M. D. A Hermenêutica Constitucional sob o Paradigma do Estado Democrático de Direito. In: COORD, M. C. In Jurisdição e Hermenêutica Constitucional. Belo Horizonte: Ed Mandamentos, 2004.

CARVALHO, K. G. Direito Constitucional: Teoria do Estado e da Constituição, Direito Constitucional Positivo. 15a . ed. Belo Horizonte: Del Rey, 2009.

CARVALHO, L. G. G. C. D. Processo penal e constituição; princípios constitucionais do processo penal. $4^{\text {a }}$. ed. Rio de janeiro: Lumen Juris.

CARVALHO, Y. C. S. A diplomacia midiática na sociedade em rede: uma análise do caso Snowden. In: CALEA - Cadernos de Aulas do LEA, Ilhéus/BA, n. 461-69, novembro 2015.

CASCAIS, F. Dicionário de Jornalismo: as palavras dos media. São Paulo: Verba, 2001. 
CASSESE, S. A crise do Estado. Tradução de Ilse Paschoal Moreira e Fernanda Landucci Ortale. Campinas: Saberes Editora, 2010.

CASTELLS, M. A era da informação: economia, sociedade e cultura. In: A Sociedade em rede. São Paulo: Paz e Terra, v. 1, 1999.

CASTELLS, M. A sociedade em rede. 6a . ed. São Paulo: Paz e terra, 1999.

CASTELLS, M. A galáxia da Internet: reflexões sobre a Internet, os negócios e a sociedade. Rio de Janeiro: Jorge Zahar, 2003.

CASTELLS, M. Internet e Sociedade em Rede. In: MORAES, D. Por uma Outra Comunicação: Mídia, Mundialização Cultural e Poder. Rio de Janeiro: Record, 2003. p. 255-288..

CATALA, P. Le droit à l'épreuve du numérique: jus ex machina. Paris: Press universitaires de France, 1998.

CERDEIRA, J. J. Cooperación internacional contra el crimen organizado. $1^{\mathrm{a}}$. ed. Buenos Aires: Ad-Hoc, 2011.

CLARKE, R. A. Securing Cyberspace Through International Norms: Recommendations for Policymakers and the Private Sector. [S.1.]: Good Harbor Security Risk Management LLC, 2012.

COELHO, L. F. Saudade do futuro: transmodernidade, direito, utopia. Curitiba: Juruá, 2007.

COLOMBO, S. A Relativização do Conceito de Soberania No Plano Internacional. Revista Eletrônica do CEJUR, Curitiba-PR, n. a. 2, v. 1, n. 3, dezembro 2008.

CONCI, L. G. A. Diálogo entre Cortes e o controle de convencionalidade - algumas reflexões sobre a relação entre o Supremo Tribunal Federal e a Corte Interamericana de Direitos Humanos. In: MENEZZETTI, L.; CONCI, L. G. A. Diálogo entre cortes: a jurisprudência nacional e internacional como fator de aproximação de ordens jurídicas em um mundo cosmopolita. Brasilia: OAB, Conselho Federal, 2015.

CONSELHO DE DIREITOS HUMANOS DA ONU. Resolução 32. Index A/HRC/32/38. ONU, 01 julho 2016. Disponivel em: $<$ https://www.article19.org/data/files/Internet_Statement_Adopted.pdf $>$. Acesso em: 01 setembro 2016.

COUTINHO, C.; LISBÔA, E. Sociedade da Informação, do Conhecimento e da aprendizagem: desafios para educação no Século XXI. Revista de Educação, Braga, v. XVIII, $\quad$ n. $1, \quad 2011 . \quad$ Disponivel em: $<$ https://repositorium.sdum.uminho.pt/bitstream/1822/14854/1/Revista_Educa\%C3\%A7\% C3\%A3o,VolXVIII,n\%C2\%BA1_5-22.pdf>. Acesso em: 02 fevereiro 2016.

CRAMPTON, J. The Political Mapping of Cyberspace. Chicago: The University of Chicago Press, 2004. 
CRAWFORD, S. The origin and development of a concept: the information society, outubro 1983. 380-385. Disponivel em: <http://www.ncbi.nlm.nih.gov/pmc/articles/PMC227258/pdf/mlab00068-0030.pdf>. Acesso em: 02 fevereiro 2016.

CRUZ, P. M. Soberania, Estado, Globalização e Crise. Argumenta Journal Law, n. 3, 2003. Disponivel em: <http://www.egov.ufsc.br/portal/sites/default/files/anexos/3277040484-1-PB.pdf>. Acesso em: 25 fevereiro 2016.

CRUZ, P. M. Soberania e Superação do Estado Constitucional Moderno. Revista de Direitos e Garantias Fundamentais, n. 2, 2007.

CUNHA JÚNIOR, D. D. Curso de Direito Constitucional. $6^{\text {a }}$. ed. Salvador: JusPODIVM, 2012.

CYNTHIA, W. Simulating sovereignty: intervention, the State and symbolic exchange. Cambridge: Cambridge University Press, 1995.

DALLARI, D. D. A. O Futuro do Estado. $2^{\text {a }}$. ed. São Paulo: Saraiva, 2007.

DALlARI, D. D. A. Elementos de Teoria Geral do Estado. 29. ed. São Paulo: Saraíva, 2010.

DARCY, A. Teoria Geral do Estado. 44a . ed. São Paulo: Globo, 2003.

DE LUCCA, N. Títulos e Contratos Eletrônicos: o advento da informática e seu impacto no mundo jurídico. In: DE LUCCA, ; SIMÃO FILHO, Direito \& Internet - aspectos jurídicos relevantes. 1. ed. Bauru/SP: EDIPRO, 2000.

DEMCHAK, C.; DOMBROWSKI, P. Rise of cybered Westephalian Age. Strategic Studies Quarterly, n. 5, 2011. Disponivel em: <http://www.au.af.mil/au/ssq/2011/ spring/demchakdombrowski.pdf>. Acesso em: 25 junho 2016.

DIAS, R.; MOHALLEM, M. F. O diálogo jurisdicional sobre direitos humanos e a ascensão da rede internacional de cortes constitucionais. Revista Brasileira de Estudos Constitucionais - RBEC, Belo Horizonte , v. 8, agosto 2014.

DIMOULIS, D.; MARTINS, L. Teoria Geral dos Direitos Fundamentais. 5a . ed. São Paulo: Atlas, 2014.

DINIZ, M. H. Dicionário Jurídico. São Paulo: Saraiva, v. 4.

DIXON, R. Transnational constitutionalism and unconstitutional constitutional amendments. Chicago Public Law and Legal Theory Working Paper Series, Chicago, n. 349, may 2011.

DOMINGUES, E. J. Os Ciberataques como um Novo Desafio para a Segurança: o Hacktivismo. Lisboa: Dissertação de Mestrado. Instituto Superior de Ciências Policiais e Segurança Interna, 2015.

DUFF., A.; CRAIG, D.; MCNEILL, D. A note on the origins of the 'information society. Journal of Information Science, Sussex, v. 22, n. 2, p. 117-122, 1996. 
ESTADOS UNIDOS, SUPREMA CORTE. Roper v. Simmons - 03-633, 2005. Disponivel em: <http://supreme.justia.com/cases/federal/us/543/03-633/,>. Acesso em: 01 setembro 2016.

EUROPEAN POLICE OFFICE. The Internet Organised Crime Theat Assessment (iOCTA), 2014. Disponivel em: <https://www.europol.europa.eu/ec3>. Acesso em: 25 junho 2016.

FACCHINI NETO, E. Reflexões histórico-evolutivas sobre a constitucionalização. do direito privado. In: SARLET, I. W. Constituição, direitos fundamentais e direito privado. Porto Alegre: Livraria do Advogado, 2003.

FERRAJOLI, L. Derechos y garantias: la ley del más débil. Tradução de Andréa Greppi. Madrid: Alianza, 1999.

FERRAJOLI, L. A soberania no mundo moderno: nascimento e crise do Estado nacional. Tradução de Carlo Coccioli e Márcio Lauria Filho Karina Jannini. São Paulo: Martins Fontes, 2002.

FERREIRA FILHO, M. G. Comentários à Constituição Brasileira de 1988. São Paulo: Saraiva, v. 3, 1994.

FERREIRA FILHO, M. G. Direitos humanos fundamentais. $3^{\text {a }}$. ed. São Paulo: Saraiva, 1999.

FERREIRA FILHO, M. G. Curso de Direito Constitucional. 27ª ed. São Paulo: Saraiva, 2001.

FERREIRA FILHO, M. G. Aspectos do direito constitucional contemporâneo. $3^{\text {a }}$. ed. São Paulo: Saraiva, 2011.

FIGUEIREDO, M. Notas a respeito da utilização de jurisprudência estrangeira pelo STF. In: Revista Brasileira de Estudos Constitucionais, RBEC, Belo Horizonte, n. 12, dezembro 2009. ano 3.

FILHO, J. H. D. A. L. Segurança Pública e sua nota de fundamentalidade no ordenamento Jurídico Brasileiro. Fortaleza: Dissertação de Mestrado. UNIFOR, 2009.

FINKLEA, K. M.; THEOHARY,. Cybercrime: Conceptual Issues for Congress and U.S. Law Enforcement. Congressional Research Service: The Library of Congress., 2013.

FIORILLO, C. A. P. O marco civil da Internet e o meio ambiente digital na sociedade da informação. São Paulo: Saraiva, 2015.

FIORILLO, C. A.; FULLER, G. P. Tutela constitucional da Internet no Brasil em face do meio ambiente digital. In: FIORILLO, C. A. P.; MARTINEZ, R. C. Os 20 anos da internet no Brasil, seus reflexos no Meio ambiambiente digital e sua tutela jurídica na sociedade da informação. 1. ed. São Paulo: FMU, v. 1, 2015.

FISCHER., R. S. A relativização do conceito de Estado e Soberania e a internalização dos Direitos Humanos. In: AUGUSTIN, S.; OLIVEIRA, M. D. Direitos Humanos: Emancipação e ruptura. Caxias do Sul: Educas, 2013. 
FONSECA JÚNIOR, R. Os Direitos Humanos na Idade Mídia. São Paulo: Montecristo, 2012.

FOUCAUlT, M. Vigiar e Punir. Tradução de Raquel Ramalhete. 28a . ed. Petrópolis: Vozes, 2002.

FRANÇA, C. C. Décision n 2008-562 DC du 21 février 2008. Paris: Journal officiel du 26 février 2008, page 3272, texte $\mathrm{n}^{\circ}$ 2., 2008. Disponivel em: <http://www.conseilconstitutionnel.fr/conseil-

constitutionnel/root/bank/download/2008562DCcc2008562dc.pdf $>$. Acesso em: 01 setembro 2016.

FREIRE, F. V.; CALDAS, A. O Ciberespaço: Desafios à Segurança e à Estratégia. Atena: Atena, 30, 90-168., 2013.

FREIRE, F. V.; NUNES, V.; ACOSTA, V. Estratégia da informação e segurança no ciberespaço. [S.1.]: Cadernos do IDN, 12, 2013.

GAUTÉRIO, M. D. F. P. O conceito de lei segundo Santo Tomás de Aquino. In: Âmbito Jurídico, Rio Grande, v. XII, n. 64, maio 2009. Disponivel em: <http://www.ambitojuridico.com.br/site/index.php?n_link=revista_artigos_leitura\&artigo_id=6279>. Acesso em: 16 março 2016.

GERCKE, M. Challenges in Developing a Legal Response to Terrorist Use of the Internet.Defence Against Terrorism. 3. ed. [S.1.]: Review, 2010.

GIBSON, W. Neuromancer. São Paulo: Aleph, 2003.

GIDDA, M. Edward Snowden anda the NSA files - timeline.. The Guardian., 25 julho 2013. Disponivel em: <http://www.theguardian.com/world/2013/jun/23/edward-snoedennsa-files-timeline? INTCMP=SRCH $>$. Acesso em: 01 junho 2016.

GONÇALVES., F. F. M. Segurança Nacional. verbete de Enciclopédia Saraiva do Direito. São Paulo.: Saraiva, v. 67.

GOULART, G. D. O Impacto das Novas Tecnologias nos Direitos Humanos e Fundamentais: O Acesso à Internet e a Liberdade de Expressão. Revista Direitos Emergentes na Sociedade Global, v. 1, n. 1, 2012. Disponivel em: $<$ http://ssrn.com/abstract=2156402>. Acesso em: 05 março 2016.

GOUVEIA, L. M. B. Sociedade de Informação: Notas de contribuição para uma definição operacional, $2004 . \quad$ Disponivel em: $<$ http://homepage.ufp.pt/lmbg/reserva/lbg_socinformacao04.pdf $>$. Acesso em: 06 fevereiro 2016.

GRAHAM, S. The End of Geography or the Explosion of Place? Conceptualizing Space, Place and Information Technology. Progress in Human Geography, v. 22, n. 2, p. 165$185,1998$.

GREENWALD, G.; MACASKILL, E. NSA program PRISM taps in touser data of Apple, Google and others. The Guardian, 06 junho 2013. Disponivel em: 
$<$ http://theguardian.com/world/2013/jun/06/us-tech-giants-nsa-data. $>$. Acesso em: 01 junho 2016.

GUERRA, S. A quarta onda globalizante e os desafios para o Direito Internacional. Revista da Faculdade de Direito de Campos, 2004. ISSN V. Disponivel em: $<$ http://www.uniflu.edu.br/arquivos/Revistas/Revista04e05/Docente/17.pdf $>$. Acesso em: 09 fevereiro 2015.

GUERRA, S. A Internet e os desafios para o direito internacional. Revista Eletrônica da Faculdade de Direito de Campos, Campos dos Goytacazes, v. 1, n. 1, novembro 2006. Disponivel em: <http://www.egov.ufsc.br/portal/sites/default/files/anexos/32792-40572-1PB.pdf>. Acesso em: 05 abril 2016.

GUERRA., E. S. D. Manual Básico. Rio de Janeiro: [s.n.], 1993.

HÄBERLE, P. Hermenêutica constitucional. Sociedade aberta de intérpretes da Constituição: contribuição para a interpretação pluralista e procedimental da Constituição. Tradução de Gilmar Ferreira Mendes. Porto Alegre: Sérgio Fabris Ed, 1997.

HÄBERLE, P. Libertad, igualdad, fraternidad: 1789 como historia, actualidad y futuro Del Estado constitucional. Madrid: Minima Trotta, 1998.

HÄBERLE, P. Pluralismo y Constitución: estúdios de Teoria Constitucional de la sociedad abierta. Tradução de Emilio Mikunda. Madrid: Tecnos, 2002.

HÄBERLE, P.. El estado constitucional. Tradução de Hector Fix-Fierro. Ciudad de México: Universidad Nacional Autônoma de México, 2003.

HÄBERLE, P. O Estado Constitucional Cooperativo. Tradução de Marcos Augusto Maliska e Elisete Antoniuk. Rio de Janeiro: Editora Renovar, 2007.

HARDING, L. Os arquivos Snowden: a história secreta do homem mais procurado do mundo. Tradução de Alice Klesck e Bruno Correia. Rio de Janeiro: LeYa, 2014.

HORBACH, C. B. Referências estrangeiras são constante no STF. In. Coluna Observatório Constitucional., Consultor Jurídico, 10.11.2012. Disponivel em: $<$ http://www.conjur.com.br/2012-nov-10/observatorio-constitucional-referenciasestrangeiras-sao-constante-stf.>. Acesso em: 03 setembro 2016.

HOUAISS, A. Dicionário Houaiss da Língua Portuguesa. Rio de Janeiro: ed. Objetiva.

INTERNET. Conceitos iniciais e histórico. Revista Brasileira de Web, 2014. Disponivel em: <http://www.revistabw.com.br/revistabw/conceitos-iniciais-e-historico-da-internet>. Acesso em: 14 fevereiro 2016.

JENTLESON, B. American Foreign Policy: The Dynamics of Choice in the 21st Century. $4^{\mathrm{a}}$. ed. Nova Iorque: Norton \& Company, 2010.

JIMENEZ, P. D. C. L. Diálogo entre cortes constitucionais é feito com mera referência? Revista Jus Navigandi, Teresina, v. 3685, n. 18, 3 agosto 2013. Disponivel em: $<$ https://jus.com.br/artigos/25090>. Acesso em: 14 setembro 2016. 
KELSEN, H. Teoria geral do direito e do estado. Tradução de Luis Carlos Borges. $3^{\text {a }}$. ed. São Paulo: Martins Fontes, 2000.

KEYSER, M. The Council of Europe Convention on Cybercrime. Journal of Transnational Law \& Policy., n. 12, p. 287-327, 2003.

KITCHIN, R. Towards Geographies of Cyberspace. Progress in Human Geography, v. 22, n. 3, p. 385-406, 1998.

KLAFKE, G. F.; BRITO, A. Hermenêutica Constitucional e diálogo entre Cortes: uma análise dos precedentes da Corte Interamericana de Direitos Humanos como elemento de interpretação no STF. In: UFAL-UFPE-UFPB:, I. E. O judiciário e o discurso dos direitos humanos. Recife: Anais do II Encontro UFAL-UFPE-UFPB, 2011.

KOEPSELL, D. R. A ontologia do ciberespaço: a Filosofia, a lei e o futuro da propriedade intelectual. São Paulo: Madras, 2004.

KOMATA, N. B. O Direito à Segurança: Uma reflexão à luz da crise de segurança pública do Estado brasileiro em face da ação das organizações criminosas. São Paulo,: Dissertação de mestrado. Universidade Presbiteriana Mackenzie. , 2009.

KRASNER, S. D. Sovereignty: organized hypocrisy. Princeton: Princeton University Press, 1999.

KUMM, M. Constitutional Democracy Encounters International Law: Terms of Engagement. New York: New York Paper 47University Public Law and Legal Theory Working Papers., 2006. Disponivel em: <http://lsr.nellco.org/nyu_plltwp/47>. Acesso em: 12 setembro 2016.

LASCALA, M. C. F. A relativização da soberania em prol dos direitos humanos. Revista de Direito Público, Londrina, v. 6, n. 2, p. 87-102, setembro 2011.

LAZZARINI, Á. Segurança nacional e segurança pública na constituição de 1988. Revista de informação legislativa, Brasilia, v. 26, n. 104, p. 233-236, dezembro 1989. Disponivel em: <http://www2.senado.leg.br/bdsf/item/id/181942>. Acesso em: 01 junho 2015.

LEMBO, C. A pessoa: seus direitos. Barueri: Manuele, 2007.

LEMOS, A. Ciberespaço e tecnologias móveis: processos de territorialização e desterritorialização na cibercultura., 2012. Disponivel em: $<$ http://www.facom.ufba.br/ciberpesquisa/andrelemos/territorio.pdf $>$. Acesso em: 14 fevereiro 2016.

LEONARDI, M. A Tutela e privacidade na Internet. São Paulo: Saraiva, 2012.

LEONARDI, M. Internet e regulação: o bom exemplo do Marco Civil da Internet. Revista do Advogado, São Paulo, v. XXXII, n. 115, abril 2012.

LEVINSON, S. Looking broad when interpreting the U.S. Constitution: some reflections. Texas International Law Journal, , v. 39353-366, 2004. 
LÉVY, P. Cibercultura. Tradução de Carlos Irineu da Costa. 1ª. ed. São Paulo: Editora 34, 1999.

LÉVY, P. O que é virtual? Tradução de Paulo Neves. São Paulo: Editora 34, 2005.

LEWANDOWSKI, E. R. Globalização, Regionalização e Soberania. São Paulo: Juarez de Oliveira, 2004.

LEWIS, P. Feinstein defends NSA data collection and insists program is 'not surveillance'. The Guardian., 2014. Disponivel em: $<$ https://www.theguardian.com/world/2013/oct/21/dianne-feinstein-defends-nsa-datacollection>. Acesso em: 01 junho 2016.

LIAROPOULOS, A. Exercising State Sovereignty in Cyberspace: An International CyberOrder Under Construction? Proceedings of the. 8th International Conference on Information Warfare and Security, março 2013.

LIMA, L. D. A.; RADDATZ, V. A (in) eficácia da privacidade na sociedade informacional. In: Salão do conhecimento - XIX Jornada de pesquisa, IJUÍ,RS, 2014.

LIMBERGER, T. Direito e informática: o desafio de proteger os direitos do cidadão. In: SARLET, I. W. Direitos Fundamentais, Informática e Comunicação: algumas aproximações. Porto Alegre: Livraria do Advogado, 2007.

LOPES, H. R.; LEMOS, N. S. Aspectos constitucionais da segurança pública. In:Âmbito Jurídico, Rio Grande, v. XIV, n. 93, outubro 2011. Disponivel em: $<$ http://www.ambitojuridico.com.br/site/?n_link=revista_artigos_leitura\&artigo_id=10490 \&rev>. Acesso em: 20 julho 2015.

LORENZETTI. Direito e internet. sao paulo: manole, 2007.

LORENZETTI, R. L. Informática, cyberlaw, e-commerce. In: LUCCA, N. D.; SIMÃO FILHO, Direito \& Internet: aspectos jurídicos relevantes. Bauru/SP: Edipro, 2000.

LORENZETTI, R. L. Comércio Eletrônico. Tradução de Fabiani Menke. São Paulo: Revista dos Tribunais, 2004.

LOSANO, M. A Informática Jurídica 20 anos depois. [S.1.]: Revista dos Tribunais, v. n. $715,1995.350-367$ p.

LUÑO, A. E. P. Impactos sociales y jurídicos de internet. Revista Argumentos de Razón Técnica, $\quad$ v. $1, \quad 1998 . \quad$ Disponivel $<$ http://institucional.us.es/revistas/argumentos/1/art_2.pdf>. Acesso em: 28 abril 2015.

MACASKILL, E. Edward Snowden, NSA files source: 'If they want to get you, in time they will'. The Guardian, 2013.

MACHADO, L. S. Ponderação e otimização do direito ao meio ambiente ecologicamente equilibrado na colisão de direitos fundamentais; uma abordagem a partir da teoria dos direitos fundamentais de Alexy. Caxias do Sul: Dissertação de Mestrado - Universidade de Caxias, 2014. 
MALISKA, M. A.. A cooperação internacional para os direitos humanos entre o direito constitucional e o direito internacional. Desafios ao Estado Constitucional Cooperativo. XVI Congresso Nacional do CONPEDI - Conselho Nacional de Pesquisa e Pós-Gradue PósGraduação em Direito, 2007, Belo Horizonte-MG. Anais do XVI Congresso Nacional do Conpedi., Florianópolis-SC:, p. Fundação Boiteux, 2007.

MARKY, T. Curso Elementar de Direito Romano. 8. ed. São Paulo: Saraiva, 1995.

MARQUES, G.; MARTINS, L. Direito da informática. Coimbra: Almedina, 2000.

MARTINS DE ARAUJO, L. C. O Diálogo Institucional entre Cortes Constitucionais: uma nova racionalidade argumentativa da jurisdição constitucional justificada pelos diálogos institucionais transnacionais. Revista da AGU , v. 39, p. 225-252, 2014.

MATTEI, U.; LUCARELli, A.; MARCOU, G. Il diritto pubblico tra crisi e ricostruzione. Roma: Deastore, 2009.

MATTELART, A. História da sociedade da informação. São Paulo: Loyola, 2002.

MATTEUCCI, N. Soberania. In: BOBBIO, N. Diccionario de Política. Brasília: UnB, 1995.

MATTEUCCI, N. El Estado Moderno: léxico y exploraciones. Madrid: Unión Editoria, 2010.

MAZZUOLI, V. D. O. Tratados internacionais de direitos humanos e direito interno. São Paulo: Saraiva, 2010.

MELLO, C. D. D. A. Direito Constitucional Internacional. São Paulo: Renova, 2000.

MELLO, C. D. D. A. Curso de Direito Internacional Público. 15ª ed. Rio de Janeiro : Renovar, v. II, 2004.

MENDES, G. F. Jurisdição constitucional. São Paulo: Saraiva, 1988.

MENDONÇA, J. J. F. D. S. Poder, Soberania e Globalização em tempo de crise do Estado Nacional. Recife: Dissertação mestrado - UFPE, 20006.

MIRANDA, J. Teoria do Estado e da Constituição. Rio de Janeiro: Editora Forense, 2002.

MIRANDA, J. Manual de Direito Constitucional. $3^{\text {a }}$. ed. São Paulo: Saraiva, 2003.

MONTEIRO, S. D. O ciberespaço: o termo, a definição e o conceito. revista de ciência da informação, artigo 03, v. 8, p. 01, junho 2007. ISSN 1981-0695.

MORAES, A. D. Direitos Humanos Fundamentais: Teoria Geral. 9ª ed. São Paulo: Atlas, 2011.

MORAES, A. D. Direito Constitucional. 31 a . ed. São Paulo: Atlas, 2015.

MORAIS DA ROSA, A. Decisão Penal: a bricolage de significantes. Rio de Janeiro,: Lumen Juris. , 2006. 
MORAIS, J. L. B. D. O Estado e suas crises. Porto Alegre: Livraria do Advogado, 2005.

MORAIS, J. L. B. D. Direitos Humanos, Estado e Globalização. In: RUBIO, D. S.; FLORES, J. H.; CARVALHO, S. D. Direitos Humanos e Globalização: Fundamentos e Possibilidades desde a Teoria Crítica. 2a . ed. Porto Alegre: Edipucrs, 2010.

NATÁRIO, R. M. O combate ao cibercrime: Anarquia e ordem no ciberespaço.. Disponivel em:

$<$ https://www.academia.edu/5619208/O_Combate_ao_Cibercrime_Anarquia_e_Ordem_no _Ciberespa\%C3\%A7o, >. Acesso em: 25 junho 2016.

NETO, A. S. O direito, a internet e o ciberespaço. Disponivel em: $<$ https://vladimirhipermidia.wordpress.com/2013/02/28/o-direito-a-internet-e-ociberespaco/>. Acesso em: 06 abril 2015.

NEY., P. Os Notáveis Erros dos Notáveis (da Comissão provisória de Estudos Constitucionais). Rio de Janeiro: Editora Forense, 1987.

NOGUEIRA, A. Globalização, regionalizações e tributação: a nova matriz mundial. Rio de Janeiro: Renovar, 2000.

NOLLKAEMPER, A. Domestic Courts and the Rule of International Law. Oxford: Oxford University Press, 2011.

NOVA ZELANDIA, CORTE DE APELAÇÃO.. Caso Hopkinson vs Police -. NZLR 704, 23 julho de 2003. Disponivel em: <http://www.lawreports.nz/hopkinson-v-police-2004-3nzlr-704/>. Acesso em: 01 setembro 2016.

NUNES, P. A definição de uma Estratégia Nacional de Cibersegurança. Nação e defesa. [S.l.]: [s.n.], v. 133, 2012.

NYE, J. S. O futuro do poder. Tradução de L. Santos. Maia: Temas e Debates., 202.

OEA. Adoção de uma estratégia interamericana integral para combater as Ameaças à Segurança Cibernética uma abordagem multidimensional e multidisciplinar para a criação de uma cultura de segurança cibernética. AG/RES.: OEA/Ser.G, CP/CSH635/04rev. 2 , 11 de maio de 2004. Disponivel em: $<$ http://scm.oas.org/doc_public/PORTUGUESE/HIST_04/CP12893P09.doc.>. Acesso em: 03 setembro 2016.

OEA; BID. Segurança Cibernética 2016 - Estamos preparados na América Latina e no Caribe? Informe de cibersegurança 2016: OBSERVATORIO DE LA CIBERSEGURIDAD EN AMÉRICA LATINA Y EL CARIBE, 2016. Disponivel em: $<$ http://www.oas.org/es/centro_noticias/comunicado_prensa.asp?sCodigo=C-030/16>. Acesso em: 01 setembro 2016.

OHMAE, K. O fim do Estado-Nação. Rio de Janeiro: Campus, 1996.

OLIVEIRA JÚNIOR, J. A. D. Teoria Jurídica e Novos Direitos. Rio de Janeiro: Lumen Juris, 2000. 
OLIVEIRA, E. L. D.; FREITAS, C. O. D. A. relações jurídicas e o mundo virtual -direitos de $5^{\text {a }}$ geração. In: CONPEDI Anais do XVII Congresso Nacional do CONPEDI. Brasilia/DF: $\quad$ [s.n.], 2008. Disponivel em: $<$ http://www.publicadireito.com.br/conpedi/manaus/arquivos/anais/brasilia/06_352.pdf>. Acesso em: 26 fevereiro 2016.

OLIVEIRA, L. H. D. Cyberwar: novas fronteiras da guerra. Brasilia: Dissertação de pósgraduação UNB. , 2011.

OLIVEIRA, R. C. R. A Constitucionalização do Direito Administrativo: o princípio da juridicidade, a releitura da legalidade administrativa e a legitimidade das agências reguladoras. Rio de Janeiro: Lumen Juris, 2008.

OLIVEIRA, R. S. A sociedade da informação: princípios e relações jurídicas. In: Âmbito Jurídico, Rio Grande, n. 95, dezembro 2011. Disponivel em: $<$ http://www.ambitojuridico.com.br/site/?n_link=revista_artigos_leitura\&artigo_id=10792 \&revista_caderno=17>. Acesso em: 28 abril 2015.

OLIVIERO, M.; CRUZ, P. M. Reflexões Sobre O Direito Transnacional. Novos estudos jurídicos, v. 17, n. 1, p. 18-28, 2012. ISSN 2175-0491. Disponivel em: $<$ http://siaiap32.univali.br/seer/index.php/nej/article/view/3635>. Acesso em: 29 março 2016.

ONU, ESCRITORIO DAS NAÇÕES UNIDAS SOBRE DROGAS E CRIMES. Comprehensive Study on Cybercrime. unodc.org, 2013. Disponivel em: $<$ https://www.unodc.org/documents/.crime/./CYBERCRIME_STUDY_210213.pdf>. Acesso em: 25 junho 2016.

OPPERMANN, D. O cenário de cibersegurança depois de Snowden e as consequências no Brasil. Conjuntura Internacional. O estado do estado., Lisboa: , v. 16, n. 1, p. 148-149, 2014. Disponivel em: <file:///D:/O_cenario_de_ciberseguranca_depois_de_Sn.pdf >. Acesso em: 01 junho 2016.

PASOLD, C. L.; FERRER, G. R.; CRUZ, P. M. Reflexões sobre o futuro do Estado constitucional moderno. Revista Brasileira de Política Pública, Brasília, v. 6, n. online, p. 21-37, 2016. Disponivel em: $<$ http://publicacoesacademicas.uniceub.br/index.php/RBPP/article/view/3862>. Acesso em: 13 setembro 2016.

PEREIRA, A. C. A. Soberania e pós-modernidade. In: BRANDT, L. N. (. O Brasil e os novos desafios do direito internacional. Rio de Janeiro: Forense, 2004.

PEREIRA, J. T. V.; CASTRO, M. F. Entre a ficção e a realidade: Os crimes cibernéticos e o Direito à segurança humana. In: CONPEDI/UFS Direito penal, processo penal e constituição. Coordenadores: Carlos Alberto Menezes, Nestor Eduardo Araruna Santiago, Paulo Cesar Correa Borges. Florianópolis: CONPEDI, 2015. p. [Recurso eletrônico on-line]. Disponivel em: <http://www.conpedi.org.br/publicacoes/c178h0tg/27g49o2w/IQUho82Y7gl1w9r9.pdf >. Acesso em: 15 março 2016.

PEZZELLA , M. C. C.; BUBLITZ, M. D. Pessoa como sujeito de direitos na sociedade da Informação: um olhar sob a perspectiva do trabalho e do empreendedorismo. Sequência, 
Florianópolis, v. 35, n. n.68, p. 239-260, junho 2014. Disponivel em: $<$ https://periodicos.ufsc.br/index.php/sequencia/article/view/2177-

7055.2013v35n68p239/26954>. Acesso em: 23 março 2016.

PILATI OLIVO, J. I.; MIKHAIL, V. Um Novo Olhar sobre o Direito à Privacidade: caso Snowden e pós-modernidade jurídica. Sequencia, Florianópolis, n. 69, p. 281-300. Disponivel em: <https://periodicos.ufsc.br/index.php/sequencia/article/view/21777055.2014v35n69p281,>. Acesso em: 22 abril 2016.

PINHEIRO, P. P. Direito Digital. 4a . ed. São Paulo: Saraiva, 2003.

PINTO, M. M. O Direito da internet: o nascimento de um novo ramo jurídico. Revista Jus Navigandi, Teresina, 2001. Disponivel em: <https://jus.com.br/artigos/2245>. Acesso em: 04 setembro 2016.

PIOVESAN, F. Direitos humanos e o direito constitucional internacional. São Paulo: Maz Limonad, 2004.

PIOVESAN, F. Diálogo no Sistema Interamericano de Direitos Humanos: desafios da reforma. Revista Campo Jurídico , n. 01, março 2013.

PIOVESAN, F. Direitos Humanos e Diálogo entre Jurisdições. Revista Brasileira de Direito Constitucional, 2012, junho.

PIRES, F. L. Introdução ao Direito Constitucional Europeu. Coimbra: livraria Almedina, 1997.

POGGIO SMANIO, G.; KIBRIT, O. Estado constitucional cooperativo e a aplicação, no brasil, do acordo de assistência judiciária em matéria penal entre brasil e estados unidos da américa. Revista Novos Estudos Jurídicos - Eletrônica, univali online, v. 20, n. 1, p. 403 429, abril 2015. ISSN 2175-0491. Disponivel em: <http://www.univali.br/periodicos>. Acesso em: 13 setembro 2016.

POLETTI, R. Introdução ao Direito. 3. ed. São Paulo: Saraiva, 1996.

POOULLET, Y. Riservatezza e Sicurezza delle reti, em Internet e Privacy: Quali Regole ? Roma: Atti del Convegno, Suplemento I Bolletino 5 Presidenza del Consiglio, 1999.

POZO, J. I. A sociedade da aprendizagem e o desafio de converter informação em conhecimento. In. Revista Pátio., Ano VIII, outubro 2004. Disponivel em: $<$ http://www.revistapatio.com.br/sumario_conteudo.aspx?id=386>. Acesso em: 02 fevereiro 2016. No 31- Educação ao Longo da Vida.

PROULX , S.; MILLETTE, M. El imperialismo digital estadounidense. In: El Estado do mundo: Anuário económico geopolítico mundial. Madrid: Ediciones Akal S.A, 2011. p. 179-182.

RABAÇA, C. A.; BARBOSA, G. G. Dicionário de comunicação. 2. ed. Rio de janeiro: Elsevier/Campus, 2001.

RAMAL, A. C. Educação na cibercultura: hipertextualidade, leitura, escrita e aprendizagem. Porto Alegre: Artmed, 2002. 
RAMOS, A. D. C. Supremo Tribunal Federal brasileiro e o controle de convencionalidade: levando a sério os tratados de direitos humanos. Revista da Faculdade de Direito, Universidade de São Paulo, São Paulo, v. 104, p. 241-286, janeiro 2009. ISSN 23.

RANIERI, N. Estado e Nação: novas relações? Política Externa, v. 13, n. 1, agosto 2004.

RANIERI, N. Teoria do Estado: do Estado de Direito ao Estado Democrático de Direito. Barueri/Sp.: Manole, 2013.

RÁO, V. O Direito e A Vida dos Direitos. São Paulo: Max Limona, v. I, 1960.

REALE, M. Teoria do Direito e do Estado. 5a . ed. São Paulo: Saraiva, 2000.

REZIO, L. L. D. S. Os Direitos Humanos na era da cibercultura: processos de interação na Página da Secretaria de Direitos Humanos no Facebook. Goiania: Dissertação de mestrado. Universidade Federal de Goiás, 2014.

RIBEIRO, F. N. C. Normas Constitucionais Programáticas: limites e possibilidades para a consolidação de Estados Constitucionais Cooperativos na Integração Latino-Americana. REBELA, v. 2, n. 2, outubro 2012.

RIO, J. J. D. O Direito Fundamental à Segurança Pública num Estado Democrático de Direito. EM TEMPO, Marília, v. 12, 2013. Disponivel em: $<$ http://galileu.fundanet.br/revista/index.php/emtempo/article/viewFile/397/324>. Acesso em: 20 abril 2016.

RIQUERT, M. A. Informática y derecho penal argentino. Buenos Aires: Ad-hoc, 1999.

ROCHA, L. A. G. S. Estado, democracia e globalização. Rio de Janeiro: Editora Forense, 2008.

ROSENAU, J. N. Distant Proximities - Dynamics beyond Globalization. New Jersey: Princeton University Press, 2003.

ROSSINI, C. Segurança cibernética na Latino América: atuação da OEA. Boletim Antivigilância, Coding Rights, 17 junho 2015. Disponivel em: $<$ https://antivigilancia.org/pt/2015/06/construa-sua-seguranca-a-atuacao-da-oea-naseguranca-cibernetica>. Acesso em: 15 janeiro 2016.

SANGUIN, A.-L. Fim da geografia ou vingança da geografia? As sociedades humanas entre um mundo liso, um mundo pontudo ou um mundo plano. Confins [Online], 2014. Disponivel em: <http://confins.revues.org/9809>.

SANTIN, V. F. Controle judicial da segurança pública: eficiência do serviço na prevenção e repressão ao crime. São Paulo: Revista dos Tribunais, 2004.

SANTOS, P. L.; CARVALHO, A. M. Sociedade da Informação: avanços e retrocessos no acesso e no uso da informação. Informação \& Sociedade: estudos., João Pessoa, v. 19, n. n.1, p. 45-55, 2009. 
SARLET, I. W. Os direitos sociais fundamentais na constituição de 1988. In: SARLET, I. W. O direito público em tempos de crise: estudos em homenagem a Ruy Rubenn Ruschel. Porto Alegre: Livraria do Advogado, 1999.

SARLET, I. W. A eficácia do direito fundamental à segurança jurídica: dignidade da pessoa humana, direitos fundamentais e proibição de retrocesso social no direito constitucional brasileiro. Revista Latino-Americana de Estudos Constitucionais., Belo Horizonte, n. 4, p. 318-365, dezembro 2004.

SARLET, I. W. A eficácia dos direitos fundamentais: uma teoria geral dos direitos fundamentais na perspectiva constitucional. $11^{\mathrm{a}}$. ed. Porto Alegre: Livraria do Advogado Editora, 2012.

SAVAGE, C.; WYATT, E.; BAKER, P. US Confirms that it gathers data overseas. The NEW York Times. Disponivel em: <http://www.nytimes.com/2013/06/07/us/nsa-verizoncalls.html?pagewanted=1>. Acesso em: 01 junho 2016.

SHANY, Y. how Supreme Is the Supreme Law of the Land - Comparative Analysis of the Influence of International human Rights Treaties upon the Interpretation of Constitutional Texts by Domestic Courts. Brook International Law Journal, v. 31, 2005.

SIEYÈS, E. J. A constituinte burguesa. Org. Aurélio Wander Bastos. Rio de Janeiro: Liber Juris, 1986.

SILVA NETTO, D. J. D. Filosofia do direito: a concepção do direito na nova sociedade. [S.1.]: sem editora, 1934.

SILVA, C. A. F. D.; SILVA, M. T. C. D. A dimensão socioespacial do ciberespaço: uma nota. Disponivel em: $<$ http://www.educacaopublica.rj.gov.br/biblioteca/geografia/0007.html $>$. Acesso em: 06 abril 2015.

SILVA, C. C. M. D. Colisão de Direitos Fundamentais no Mundo Virtual. Ambito Jurídico. Disponivel em: <http://www.ambitojuridico.com.br/site/index.php?n_link=revista_artigos_leitura\&artigo_id=1011>. Acesso em: 15 abril 2015.

SILVA, C. M. D. A. Do monismo estatal ao pluralismo jurídico. Boletim Jurídico, Uberaba/MG, v. 4, n. 164, setembro 2016. Disponivel em: $<$ http://www.boletimjuridico.com.br/ doutrina/texto.asp?id=1057>. Acesso em: 26 junho 2016.

SILVA, C. O. P. D. O futuro do Estado e da interpretação Constitucional sob a ótica da Doutrina de Peter Häberle.Estado Constitucional Cooperativo. Revista Jurídica da Presidencia, Brasilia, v. 7, n. 72, 2005.

SILVA, C. O. P. D. Transjusfundamentalidade: Diálogos Judiciais Transnacionais sobre Direitos Fundamentais. Brasília.: Tese (Doutorado em Direito) - Universidade de Brasília. 276f, 2013.

SILVA, J. A. D. Comentário Contextual à Constituição. $8^{\mathrm{a}}$ ed., atual. Até a Emenda Constitucional 70, de 22.12.2011. ed. São Paulo: Malheiros Editores, 2012. 
SILVA, J. A. D. Curso de Direito Constitucional Positivo. $37^{\text {a }}$ ed. São Paulo: Maheiros, 2014.

SILVA, L. M. D. S. . Soberania: uma reconstrução do princípio, da origem à pósmodernidade. In: OLIVEIRA, M. L. (. ). O sistema interamericano de proteção dos direitos humanos: interface com o direito constitucional contemporâneo. Belo Horizonte: Del Rey, 2007.

SILVA, S. M. L. D. A Ciberespionagem no contexto Português. Lisboa: Dissertação de Mestrado em Guerra da Informação no Departamento de Estudos de pós-graduação da Academia Militar Portuguesa, 2014.

SILVA, V. A. D. Integração e diálogo constitucional na América do Sul. In: ARMIN VON BOGDANDY / FLÁVIA PIOVESAN / MARIELA MORALES ANTONIAZZI (ORGS.) Direitos humanos, democracia e integração jurídica na América do Sul. Rio de Janeiro: Lumen Juri, 2010.

SILVEIRA, V. O. D.; CAMPELLO, L. G. B. Cidadania e direitos humanos. In: MORAES, A. D.; KIM, R. P. Cidadania: o novo conceito jurídico e a sua relação com os direitos fundamentais individuais e coletivos. São Paulo: Atlas, 2013.

SLAUGHTER, A.-M. A global community of courts. Cambrigde: Harvard International Law Journal, , v. 44, 2003.

SLAUGHTER, A.-M. A New World Order. Princeton: Princeton University Press, 2004.

SLAUGHTER, A.-M. Sovereignty and power in a networked world order. Stanford: Stanford Journal of International Law, 2004.

SNOWDEN, E. Carta aberta ao povo do Brasil.. Jornal Folha de SP, 23 jan. 2013. Disponivel em: <http://forum.antinovaordemmundial.com/Topico-carta-aberta-ao-povodobrasil-edward-snowden\#ixzz3HvXBz9Pu>. Acesso em: 01 junho 2016.

SOUZA JUNIOR, C. S. Consenso e tipos de Estado no Ocidente. Porto Alegre: Editora Sagra Luzzatto, 2002.

SPERTI, A. Il dialogo tra le Corti Constituzionale ed il ricorso alla omparazione giuridica nella esperienza piu recente. In Rivista Di Diritto Constituzionale, Giappichelli Edtore. Torino, 1996.

SPIEGEL, S. Traditional Space Versus Cyberspace: The Changing Role of Geography in Current International Politics. Geopolitics, v. 5, n. 3, p. 114-125, 2000.

STRANGE, S. The retreat of the State: the diffusion of Power in the world economy. Cambridge: Cambridge University Press, 1997.

STRECK, L. L.; MORAIS, J. L. B. D. Ciência Política e Teoria do Estado. 7ª ed. Porto Alegre: Livraria do Advogado, 2012.

TAVARES, A. R. Paradigmas do judicialismo constitucional. São Paulo: Saraiva, 2012. 
TUSHNET, M. Inevitable globalization of constitutional law.. Virginia Journal of International Law, v. 49, n. 4, p. 985-1005, 2009.

UNESCO. Recommendation Concerning The Promotion And Use Of Multilingualism And Universal Access To Cyberspace. Unesco.org. Disponivel em: <Disponível em: http://portal.unesco.org/ci/en/file_download.php/41e32bf91c3d30c7855cefe4251cba6fRec ommendation-Eng.pdf $>$. Acesso em: 18 maio 2016.

VALENTE, M. G. Segurança: Um tópico jurídico em construção. Lisboa: Âncora Editora, 2013.

VERGOTTINI, G. D. Il dialogo tranznacionale fra le Corti. Napoles: Editoriale Scientifica, 2010.

VERGOTTINI, G. D. Otre il dialogo tra Corti: Giudici, diritto straniero, comparazione. Bologna: Il Mulino, 2010.

WACHELESKI, M. P. O declínio do Estado Nacional e a nova realidade da jurisdição. Revista Eletrônica Direito e Política, Itajai, v. 1, n. 1. Disponivel em: $<$ www.univali.br/direitoepolitica>. Acesso em: 01 junho 2016.

WALDRON, J. Foreign law and the modern ius gentium. Harvard : Harvard Law Review, v. 129, 2005.

WEIS, C. Direitos Humanos Contemporâneos. São Paulo: Malheiros, 1999.

WILSON, C. Botnets, Cybercrime, and Cyberterrorism: Vulnerabilities and Policy Issues for Congress. Congressional Research Service: The Library of Congress, 2008.

ZIZEK, S. Um mapa da ideologia. Tradução de Vera Ribeiro. Rio de Janeiro,: Contraponto, 1996. 